\title{
High surface area bio-waste based carbon as a superior electrode for vanadium redox flow battery
}

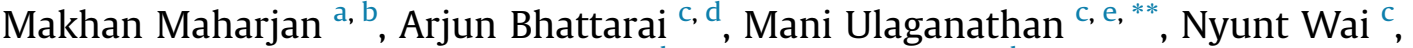 \\ Moe Ohnmar Oo ${ }^{c}$, Jing-Yuan Wang ${ }^{\text {a, }}{ }^{\text {, }}$, Tuti Mariana Lim ${ }^{\text {b, * }}$ \\ ${ }^{a}$ Residues and Resource Reclamation Centre (R3C), Nanyang Environment and Water Research Institute (NEWRI), Nanyang Technological University, \\ CleanTech One, 637141, Singapore \\ b School of Civil and Environmental Engineering, Nanyang Technological University, 50 Nanyang Avenue, 639798, Singapore \\ c Energy Research Institute @Nanyang Technological University (ERI@N), Singapore \\ ${ }^{\mathrm{d}}$ School of Material Science and Engineering, Nanyang Technological University, Singapore \\ e Central Electrochemical Research Institute, Karaikudi 630 006, Tamilnadu, India
}

\section{H I G H L I G H T S}

- High surface area activated carbon was synthesized from orange peel (OP-AC).

- OP-AC showed high porous structure and rich oxygen-containing functional groups.

- OP-AC coated electrode showed less contact resistance and good catalytic activity.

- OP-AC coated electrode enhanced voltage and energy efficiency in VRB static cell.

\section{A R T I C L E I N F O}

\section{Article history:}

Received 13 February 2017

Received in revised form

29 May 2017

Accepted 4 July 2017

Available online 11 July 2017

\section{Keywords:}

Vanadium redox flow battery

Porous activated carbon

Electro-catalytic activity

Citrus sinensis peel

\begin{abstract}
A B S T R A C T
Activated carbon (AC) with high surface area $\left(1901 \mathrm{~m}^{2} \mathrm{~g}^{-1}\right)$ is synthesized from low cost bio-waste orange (Citrus sinensis) peel for vanadium redox flow battery (VRB). The composition, structure and electrochemical properties of orange peel derived AC (OP-AC) are characterized by elemental analyzer, field emission-scanning electron microscopy, X-ray diffraction, Raman spectroscopy, X-ray photoelectron spectroscopy, cyclic voltammetry (CV), and electrochemical impedance spectroscopy. CV results show that OP-AC coated bipolar plate demonstrates improved electro-catalytic activity in both positive and negative side redox couples than the pristine bipolar plate electrode and this is ascribed to the high surface area of OP-AC which provides effective electrode area and better contact between the porous electrode and bipolar plate. Consequently, the performance of VRB in a static cell shows higher energy efficiency for OP-AC electrode than the pristine electrode at all current densities tested. The results suggest the OP-AC to be a promising electrode for VRB applications and can be incorporated into making conducting plastics electrode to lower the VRB cell stack weight and cost.
\end{abstract}

(C) 2017 Elsevier B.V. All rights reserved.

\section{Introduction}

Energy storage systems such as flow batteries, supercapacitors (Li-ion and $\mathrm{Na}$-ion), etc. play an important role in renewable energy

\footnotetext{
* Corresponding author. School of Civil and Environmental Engineering, Nanyang Technological University, Singapore.

** Corresponding author. Energy Research Institute @Nanyang Technological University (ERI@N), Singapore.

E-mail addresses: nathanphysics@gmail.com (M. Ulaganathan), tmlim@ntu.edu. sg (T.M. Lim).
}

integration. The technical and financial constraints, however, have limited extensive utilization of all systems [1,2]. Redox flow batteries are considered to be promising candidates for large scale energy storage and have higher cycle efficiency and long-life. Among the different flow batteries, the vanadium redox flow battery (VRB) has drawn huge interest in recent years owing to its several advantages such as no issues with the cross-mixing of two half-cell electrolytes, ambient temperature operation, environmentallyfriendly technology and long cycle life [3,4]. Nevertheless, present VRB systems is considered expensive, mainly due to the stackrelated components [5,6] and electrolyte costs. This has given 
opportunities to investigate VRB in several aspects, such as development of cost effective and efficient electrodes [6-8], and others $[9,10]$. The electrode, that provides reaction sites for the redox reactions, is one of the key components of battery. The properties of an electrode play a crucial role in determining electrochemical performance of VRB. Thus, the search for low cost and promising alternative material as electrode is necessary to help reduce the cost.

Activated carbon (AC) possesses attractive features (e.g., high surface area, good conductivity, low cost) towards the effective treatment of aqueous solutions and improvement of electrochemical performance, among others. Numerous literature are available on use of AC as electrode in supercapacitors for energy storage applications or for other purposes [11-14]. Furthermore, researchers have extensively investigated AC preparation with tailored textural properties via various synthesis routes, and have also employed different precursors [15-17]. Biomass is a low-cost, abundantly available and environmentally-friendly renewable resource, which has drawn huge attention for AC preparation in recent years.

In the present work, orange (Citrus sinensis) peel was employed as a precursor for the preparation of $A C$ in consideration of its abundance. The worldwide production of orange in 2016/17 was reported around 49.6 million metric tons [18]. In regions with large orange production, the peels pose a serious disposal problem [19]. Research works have reported the use of orange peels for producing hydrochars as adsorbent for metallic ions from aqueous solutions [20-24], and ACs as adsorbents for dyes and organic contaminants $[19,25,26]$.

In VRB, graphite or carbon based bipolar plates are commonly used as supporting electrodes, and graphite felts serve as active electrodes. The use of thick bipolar plates increases the weight of the stack, which limits power capability of the VRB system. Due to this, carbon based conducting plastics are proposed for graphitic electrodes in commercial systems. Again, such plastics have concerns of poor conductivity that deliver lower cell efficiencies. There have been enormous attempts to catalyze charge transfer reactions for improving overall VRB performance [27-30]. Recently, we reported the enhanced electro-catalytic activity of AC (derived from coconut shell) modified toray paper electrode in VRB with multicouple reactions [6]. Reports on the use of biomass-derived AC as electrode in VRB application are scarce. So far, orange peel derived AC (thereafter called OP-AC) has not been studied as electrodes in any flow battery applications. As a low-cost, environmentallyfriendly and sustainable product, a study on the potential of using bio-waste derived AC as electrode in electrochemical devices (such as VRB) is needed.

In this work, we synthesized highly porous activated carbon from orange peel via chemical activation process. The synthesized OP-AC was subjected to extensive characterization. For the first time, we evaluated performance of the OP-AC modified bipolar plate electrodes in VRB applications.

\section{Experimental section}

\subsection{Synthesis of activated carbon from orange peel}

High surface area activated carbon (AC) was synthesized from abundant renewable resource, orange peel (Citrus sinensis). Briefly, cleaned orange peels cut into small pieces were dried at $60{ }^{\circ} \mathrm{C}$ in an oven for $12 \mathrm{~h}$. Dried peels were ground using ball mill and sieved (300 $\mu \mathrm{m}$ aperture) to obtain yellow colored fine orange peel powder (OP). The weighed amount of OP was heated in a reactor to $400{ }^{\circ} \mathrm{C}\left(5{ }^{\circ} \mathrm{C} \mathrm{min}^{-1}\right)$ under argon atmosphere $\left(50 \mathrm{~mL} \mathrm{~min}^{-1}\right)$ with dwelling for $1 \mathrm{~h}$, then cooled to ambient temperature. For chemical activation, the obtained char was impregnated with $\mathrm{KOH}(\mathrm{KOH}$ :char from $\mathrm{OP}=2: 1$ by weight) by dissolving $\mathrm{KOH}$ in minimal MilliQ water and thoroughly mixing with the char to form a thick paste. The paste dried at $105{ }^{\circ} \mathrm{C}$ was carbonized in a tubular furnace (Carbolite) to $800{ }^{\circ} \mathrm{C}\left(5^{\circ} \mathrm{C} \mathrm{min}^{-1}\right)$ with $50 \mathrm{~mL} \mathrm{~min}{ }^{-1}$ argon, and dwelled for $2 \mathrm{~h}$ followed by cooling down to ambient temperature. The resultant product was ground, then washed with $1 \mathrm{M} \mathrm{HCl}$ for removing inorganics present, and washed repeatedly with Milli-Q water until washed solution measured neutral $\mathrm{pH}$ value. The washed product was vacuum dried at $80{ }^{\circ} \mathrm{C}$ for overnight, designated as OP-AC and stored in desiccators for further studies.

\subsection{Material characterizations}

The elemental contents of OP and OP-AC were obtained from the elemental analyzer (vario EL cube CHNOS, Germany). The surface morphology and structure of OP-AC were examined by field emission-scanning electron microscopy (FE-SEM, JEOL JSM-7600F). The X-ray diffraction (XRD) pattern was studied employing Bruker AXS, D8 Advance equipped with $\mathrm{Cu}-\mathrm{K}_{\alpha}$ radiation. Raman spectra were obtained using a Witec Alpha 300 SR (Argon Laser, $514 \mathrm{~nm}$, $25 \mathrm{~mW}$ ). Surface functional groups were obtained from X-ray photoelectron spectroscopy (XPS) using Multilab 2000, Thermo Scientific, UK with monochromator and AlK $\alpha$ radiation $(\mathrm{h} v=1486.6 \mathrm{eV})$. For textural properties, the sample was first degassed and analyzed with nitrogen as adsorbate at $77.35 \mathrm{~K}$ using Quadrasorb Automated Surface Area and Pore Size Analyzer (Nova3000 Series, Quantachrome). The surface area of OP-AC was obtained from the Brunauer-Emmette-Teller (BET) method with the adsorption in the relative pressure $\left(\mathrm{P} / \mathrm{P}_{\mathrm{O}}\right)$ of 0.10 . The total pore volume $\left(V_{T}\right)$ was derived from the amount of nitrogen adsorbed at a relative pressure of 0.95 . The micropore volume $\left(\mathrm{V}_{\text {micro }}\right)$ and micropore surface area $\left(S_{\text {micro }}\right)$ were obtained from t-plot method with a relative pressure of $0.15-0.5$. The pore size distribution (PSD) was measured from the desorption points using DFT pore size distribution.

\subsection{Electrochemical measurements}

\subsubsection{Electrodes preparation}

First, OP-AC (90 wt\%) and polyvinylidene fluoride (PVdF) as binder (10 wt\%) were thoroughly mixed and homogenous slurry was made by dispersing the mixture in $\mathrm{N}$-Methyl-2-pyrrolidone (NMP) solution. For electrochemical tests, the electrodes were prepared with a coat of slurry onto one surface of $0.6 \mathrm{~mm}$ thick expanded graphite plates (TF6 from SGL Carbon, Germany). The electrodes with coat areas of $1 \mathrm{~cm}^{2}(1 \mathrm{~cm} \times 1 \mathrm{~cm})$ for CV and EIS measurements, and $4.0 \mathrm{~cm}^{2}(2.0 \mathrm{~cm} \times 2.0 \mathrm{~cm})$ for a VRB static cell testing were prepared. In both cases, the coated amount of slurry onto bipolar plate surface was $30 \mu \mathrm{L} \mathrm{cm}^{-2}$. The slurry loaded plates were dried in an oven at $60{ }^{\circ} \mathrm{C}$ for overnight.

\subsubsection{Cell assembly}

In the assembly, PAN based carbon felt (SIGRACELL GFD 4.6 EA, SGL Carbon, Meitingen, Germany) of thickness $4.6 \mathrm{~mm}$ and bipolar plate (TF6, SGL Carbon) of thickness $0.6 \mathrm{~mm}$ were used. The OP-AC coating had a thickness of $\sim 0.3 \mathrm{~mm}$. The thickness of the carbon felt reduced to $\sim 3.0 \mathrm{~mm}$ after compression. Therefore, the OP-AC coating layer was about $10 \%$ of the total thickness. The OP-AC coated bipolar plate was in contact with the porous graphite felt and the other side of the plate was in contact with the copper plate, similar to a conventional VRB configuration. An anion exchange membrane (FAP 450, Fumatech, GmbH, Bietigheim, Germany) was used to separate the two half-cells. In the assembly, a stainless steel plate was kept at the end of both half-cells for tightening. The 
electrolyte concentration was $1.6 \mathrm{M} \mathrm{V}^{3.5+}$ in $4.5 \mathrm{M}$ total sulphate (GFE, Nuremberg, Germany). For all tests, identical bipolar plates, felts, electrolytes and membrane were used, so the effect of coating on both half-cells was supposed to be equal. The arrangement of the cell components in a half-cell is shown in Fig. 1.

\subsubsection{Performance test}

The electrochemical performance of OP-AC was assessed by cyclic voltammograms (CV) along with electrochemical impedance spectra (EIS) using a multi-channel potentiostat (VMP3, Bio-Logic Science Instruments, France). The measurements were performed in an electrochemical cell using the bipolar plate electrode (both coated and non-coated), platinum wire and saturated calomel electrode (SCE) as working, counter and reference electrodes, respectively. The OP-AC coated bipolar plate was dipped into the electrolyte (mixture of $50 \% \mathrm{~V}^{3+}$ and $50 \% \mathrm{~V}^{4+}$ ) and the non-coated side was connected to potentiostat probe to make it working electrode. CVs were obtained within the voltage window of $-1.0-1.6 \mathrm{~V}$ (vs. SCE) at various scan rates. EIS were performed separately for both redox couples at $50 \%$ state of charge (SOC) and were measured in the frequency range from $100 \mathrm{kHz}$ to $100 \mathrm{mHz}$ at AC signal of $10 \mathrm{mV}$.

The performance of OP-AC OP-AC coated bipolar plate was further evaluated in a VRB static cell described in section 2.3.2 using $1.6 \mathrm{M} \mathrm{V}^{3.5+}$ in $4.5 \mathrm{M}$ total sulphate as electrolyte at room temperature with a Battery Testing System (NEWARE, China). The chargedischarge cycles were carried out at different current densities of 5 , 10,15 and $20 \mathrm{~mA} \mathrm{~cm}^{-2}$ ( 5 cycles for each current density) with cutoff voltage between 1.6 and $0.9 \mathrm{~V}$. The coulombic, energy and voltage efficiencies of the cell were calculated from the chargedischarge profiles.

\section{Results and discussion}

\subsection{Material physico-chemical properties}

The elemental analysis results reveal high carbon content in orange peel (OP), and the carbon content increased from $40.9 \%$ in OP to $80.8 \%$ in OP-AC (Table 1), which is in close agreement with previous study [19].

Nitrogen adsorption-desorption studies of OP-AC depict a combination of both type I and IV isotherms (Fig. 2a) [31]. The nitrogen adsorption at very low relative pressure reflects the

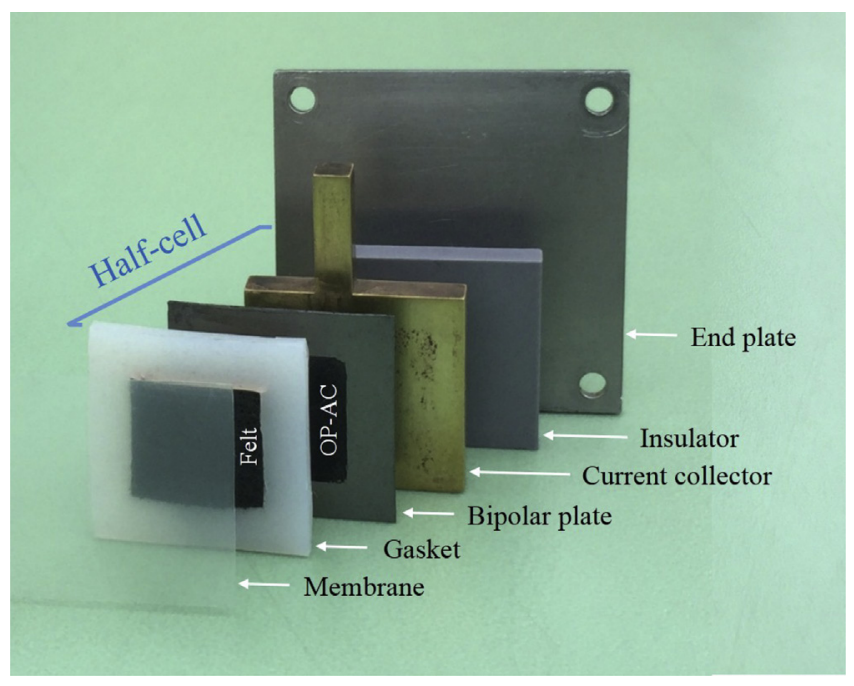

Fig. 1. A half-cell arrangement of components used in static cell test.
Table 1

Elemental composition of OP and OP-AC (wt\%).

\begin{tabular}{lllllll}
\hline Sample & $\mathrm{C} \%$ & $\mathrm{H} \%$ & $\mathrm{~N} \%$ & $\mathrm{~S} \%$ & $\mathrm{O}^{\mathrm{a}}$ & Reference \\
\hline OP & 43.0 & 5.9 & 0.9 & 0.0 & 50.2 & {$[19]$} \\
OP-AC & 82.5 & 2.5 & 0.9 & 0.0 & 14.1 & {$[19]$} \\
OP & 40.9 & 6.1 & 0.8 & 0.2 & 52.0 & This study \\
OP-AC & 82.8 & 1.3 & 0.5 & 0.2 & 15.2 & This study \\
\hline
\end{tabular}

a Estimated by difference.

predominance of micropores, and a tiny hysteresis loop indicates the existence of some mesopores. The BET surface area, micropore surface area and mesopore surface area are calculated to be 1901 , 1407 and $494 \mathrm{~m}^{2} \mathrm{~g}^{-1}$, respectively. The total pore volume is $0.94 \mathrm{cc}$ $\mathrm{g}^{-1}$ with micropore volume of $0.59 \mathrm{cc} \mathrm{g}^{-1}$. The inset in Fig. 2a shows relatively narrow pore size distribution (PSD), centered at $11.26 \AA$ pore width. Fig. 2b shows FE-SEM image of OP-AC with welldeveloped pores and porous network-like structure. The obtained different values of typical pore width are due to the pores with a width of $11.26 \AA$ A that are invisible in Fig. 2b, however, their quantity is significantly more than the quantity of pores with a width of $1 \mu \mathrm{m}$. Some large pores may have formed due to the enlargement of small pores with more $\mathrm{CO}_{2}$ release during the activation process. The creation of interconnected pores with high surface area is attributed to intercalation of $\mathrm{K}^{+}$ions into the lamellae of the crystallites during activation. The porous network allows fast ion diffusion and the high surface area makes available of more active sites for the electrical double layer formation across the electrode/ electrolyte interface.

The diffraction patterns of OP-AC from crystallographic study by XRD are shown in Fig. 3a. Two broad peaks around $2 \theta$ values of $29.5^{\circ}$ and $43.0^{\circ}$ can be seen, which are matched to the (002) and (110) planes of the graphite structure in the carbon based materials, respectively. The observed peaks suggest amorphous semigraphitic carbon [32,33]. Raman spectroscopy is considered as a non-destructive technique commonly used to elucidate ordered, defective or disordered crystal structures of carbon. Fig. 3b displays Raman spectrum of OP-AC; there are two main peaks that correspond to different features of carbon materials. The $\mathrm{D}$ band (at $\sim 1371 \mathrm{~cm}^{-1}$ ) is attributed to the disorder or defect intervened zoneedge (near K-point) phonons. The $\mathrm{G}$ band (at $\sim 1604 \mathrm{~cm}^{-1}$ ) is associated to the in-plane vibration of $\mathrm{sp}^{2}$ atoms present in carbon materials. The ratio between the intensities of the $D$ and $G$ bands $\left(I_{\mathrm{D}} / I_{\mathrm{G}}\right)$ is used to predict the presence of defects within the samples. The $I_{\mathrm{D}} / I_{\mathrm{G}}$ ratio is calculated to be 0.99 , indicating the existence of substantial amounts of defects and disordered structures in the sample [34,35]. The elemental compositions on the sample surface were identified by XPS analysis. The wide survey spectra of OP-AC are illustrated in Fig. 3c, which reveals the existence of carbon and oxygen. Fig. 3d shows the existence of different functionalities on the sample along with the corresponding high resolution deconvoluted C 1s band spectra. The C1s spectra of the samples can be fitted by five individual component peaks. The peaks at $284.5 \mathrm{eV}$ and 285.4 are assigned to $\mathrm{sp}^{2} \mathrm{C}=\mathrm{C}$ and $\mathrm{sp}^{3} \mathrm{C}-\mathrm{C}$ while the peaks at 286.7, 288.6 and $291.4 \mathrm{eV}$ correspond to $\mathrm{C}-\mathrm{O}, \mathrm{C}=\mathrm{O}$ and $\pi-\pi^{*}$, respectively [36]. The $\mathrm{sp}^{2}$ configuration forms $\pi-\pi^{*}$ bands, whereas $\mathrm{sp}^{3}$ creates $\sigma-\sigma^{*}$ spectra from the localized density of states formation. The percentage of $\mathrm{sp}^{2} \mathrm{C}=\mathrm{C}$ and $\mathrm{sp}^{3} \mathrm{C}-\mathrm{C}$ are calculated to be $58.0 \%$ and $18.9 \%$, followed by $11.6 \%, 11.1 \%$ and $0.5 \%$ for $\mathrm{C}=\mathrm{O}, \mathrm{C}-\mathrm{O}$ and $\pi-\pi^{*}$ groups, respectively. The results show the presence of a large number of oxygen containing functional groups $(\mathrm{C}=\mathrm{O}$ and $\mathrm{C}$ $\mathrm{O}$ ) on the surface of OP-AC, which are beneficial for better electrochemical processes. 

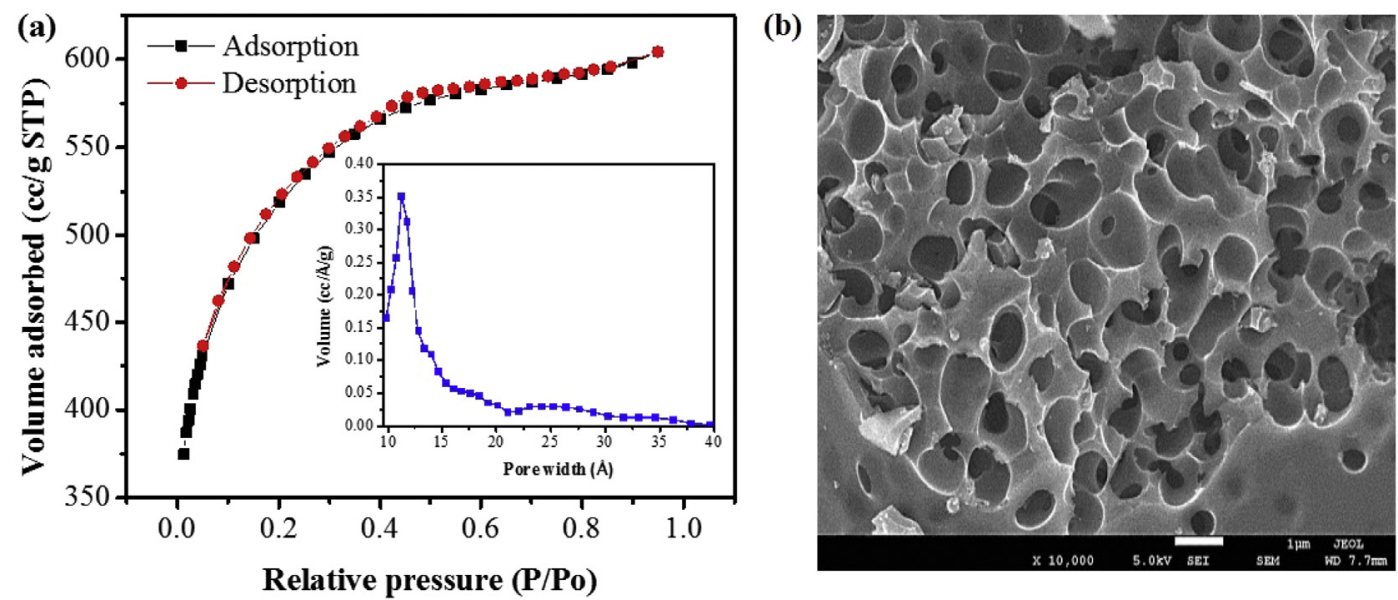

Fig. 2. (a) Nitrogen adsorption-desorption isotherm and pore size distribution (inset in Fig. 2a), and (b) FE-SEM image of OP-AC.
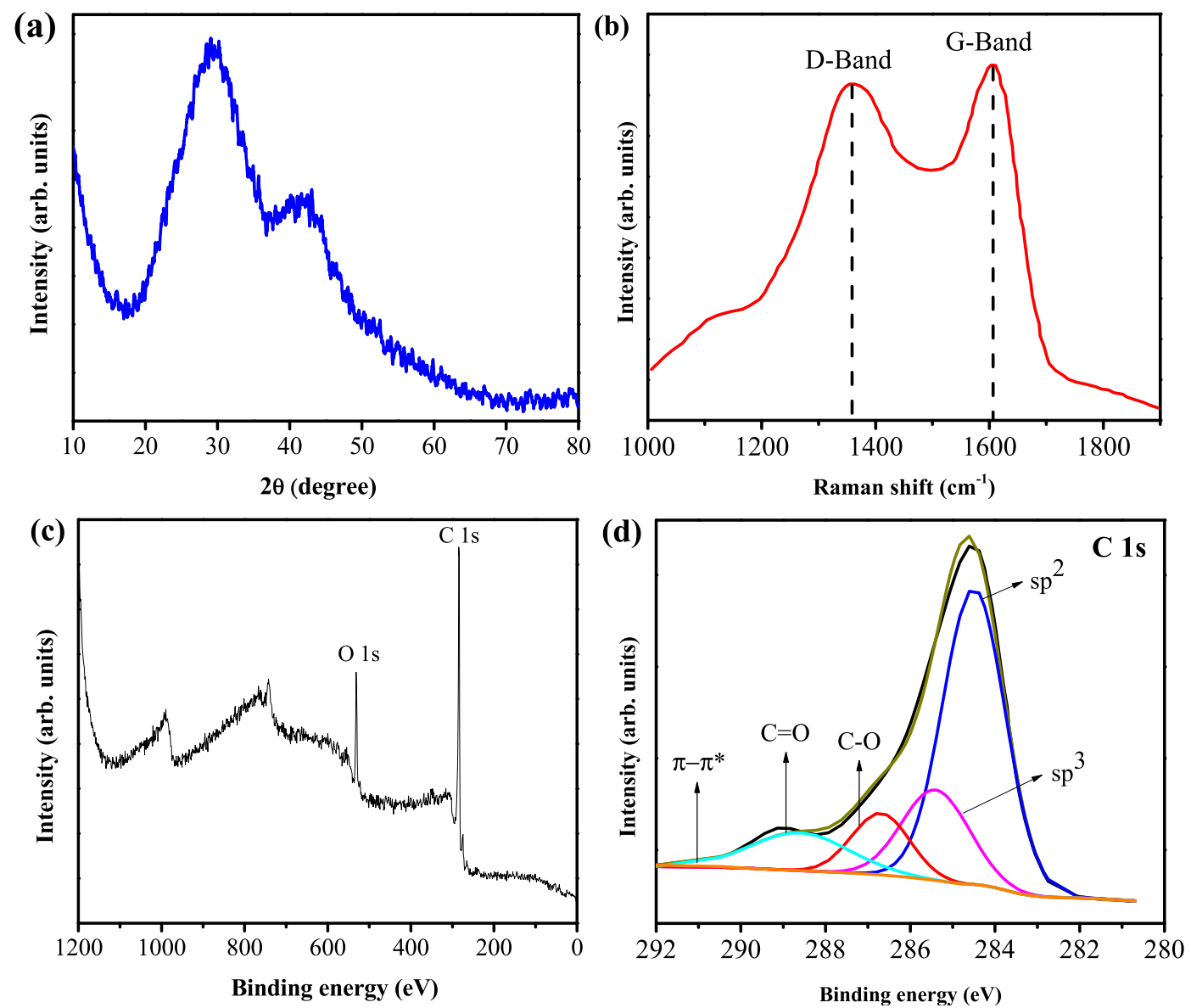

Fig. 3. (a) XRD spectra, (b) Raman spectra, (c) XPS survey spectra, and (d) C1s spectra of OP-AC.

\subsection{Electrochemical behavior}

Fig. 4 depicts the CV curves of both pristine and OP-AC modified bipolar plate electrodes in $1.6 \mathrm{M} \mathrm{V}^{3.5+}$ in $4.5 \mathrm{M}$ total sulphate solution as electrolyte at a scan rate of $5 \mathrm{mV} \mathrm{s}^{-1}$. The $\mathrm{CV}$ curves exhibit two redox couples $\mathrm{V}^{2+} / \mathrm{V}^{3+}$ and $\mathrm{V}^{4+} / \mathrm{V}^{5}$ on negative and positive sides, respectively. Higher anodic and cathodic peak currents are observed in OP-AC coated electrode than the pristine electrode, indicating higher electro-catalytic activities for both redox couples.
This is likely due to the increase of surface area and the presence of oxygen-containing functional groups on the surfaces of the OP-AC. Additionally, the presence of oxygen containing functional groups in OP-AC enhances hydrophilic properties, thus improving the wettability of the electrode in the aqueous electrolyte and faster electron transfer.

In order to gain more understanding on the electrochemical processes, EIS was measured for both pristine and OP-AC coated bipolar plates and the results are shown in Fig. 5. The Nyquist plots 


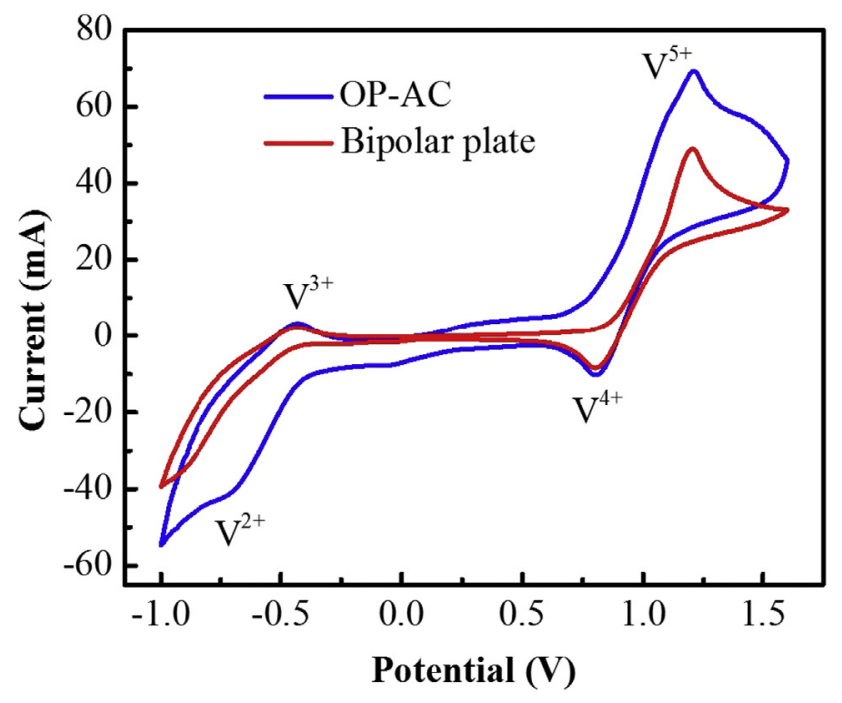

Fig. 4. Cyclic voltammograms (CV) with or without OP-AC onto bipolar plate as working electrodes in $1.6 \mathrm{M} \mathrm{V}^{3.5+}$ in $4.5 \mathrm{M}$ total sulphate at a scan rate of $5 \mathrm{mV} \mathrm{s}^{-1}$.

comprise of a semicircle that arises from the ohmic resistance and charge transfer reaction (electrolyte/electrode interface), and a linear part which is related to the diffusion of vanadium ion through pore channel of the electrode. To compare the charge transfer resistance between pristine and OP-AC coated bipolar plates, the high frequency intercept are moved to the same point. The inset diagram in each figure shows the original spectra prior to moving the high frequency intercept. The high frequency for the OP-AC coated electrodes is clearly much lower than the pristine electrode, indicating contact improvement at the interface between the porous felt and bipolar plate. The impedance results show that the charge transfer resistance for the pristine electrode $(3.60 \Omega)$ is nearly twofold compared with OP-AC coated bipolar plate (1.83 $\Omega$ ) in negative $\left(\mathrm{V}^{2+} / \mathrm{V}^{3+}\right)$ electrolyte (Fig. 5a). Similarly, the charge transfer resistance are calculated to be 0.30 and $0.25 \Omega$ in positive $\left(\mathrm{V}^{4+} / \mathrm{V}^{5+}\right)$ electrolyte for pristine and OP-AC coated bipolar plates, respectively (Fig. 5b). The lower charge transfer resistance of OP-AC improves the electrochemical reaction. Overall, CV and EIS results indicate that the improved electro-catalytic activity, and reduced charge transfer resistance of OP-AC can be ascribed to the synergistic effect of high surface area and the presence of oxygencontaining functional groups on the surface of OP-AC.

\subsection{VRB cell performance}

Fig. 6a presents the charge-discharge profiles of the cell with pristine and OP-AC coated bipolar plates at current density of $5 \mathrm{~mA} \mathrm{~cm}{ }^{-2}$. As can be seen, the OP-AC coated bipolar plate maintains stable charge-discharge performance and exhibits enhanced capacity compared with the pristine electrode. Comparison of voltage and energy efficiencies of the cells with bipolar plate and OP-AC coated bipolar plates at different current densities are shown in Fig. $6 \mathrm{~b}$ and c, respectively. The cell employing OP-AC coated bipolar plate exhibits higher energy and voltage efficiencies at all current densities tested, which can be due to the improved electrochemical activity, and better contact between porous felt and bipolar plate interface.

The porosity of the graphite felt was reduced to about $87 \%$ after compression. Considering the 10\% contribution of OP-AC coated layer with respect to total thickness of active layer and $66 \%$ porosity against $87 \%$ porosity of graphite felt, the electrolyte volume of about $8 \%$ would likely reach the OP-AC coated layer effectively resulting in improved electrochemical reaction, as indicated in the $\mathrm{CV}$ result. In addition, the presence of rich oxygen functional groups as evidenced by XPS results should also contribute to the improved electrochemical performance. Recent studies have also reported surface oxygen groups playing catalytic role on redox reaction kinetics that determine overall VRB performance [27,28,37].

It should be noted that the estimated $8 \%$ of electrolyte reaching the coating layer is valid as electrolyte was contained in the porous electrode in a static cell. In a conventional flow cell, the permeability will further reduce according to Carman-Kozeny equation for porous media flow. Therefore, the electrochemical contribution might be negligible in a flow cell, however, the contribution of the improved contact resistance will still be effective.

In order to assess the performance stability, the cells were further tested at a constant current density of $20 \mathrm{~mA} \mathrm{~cm}^{-2}$ for 100 cycles (Fig. 7). The OP-AC coated layer remained intact without peel off after long term test. Table 2 presents the average coulombic efficiency (CE), energy efficiency (EE) and voltage efficiency (VE) values at different current densities. The voltage and energy efficiencies decrease at higher current densities which are due to the increased $i R$ drops with increase in current densities. A slight decreasing of energy efficiency with time during long-term cyclic operation was possibly due to side reactions, collector surface passivation, etc. $[38,39]$. The cell performance in present study are superior to the previously reported study with coconut shell derived AC [6].
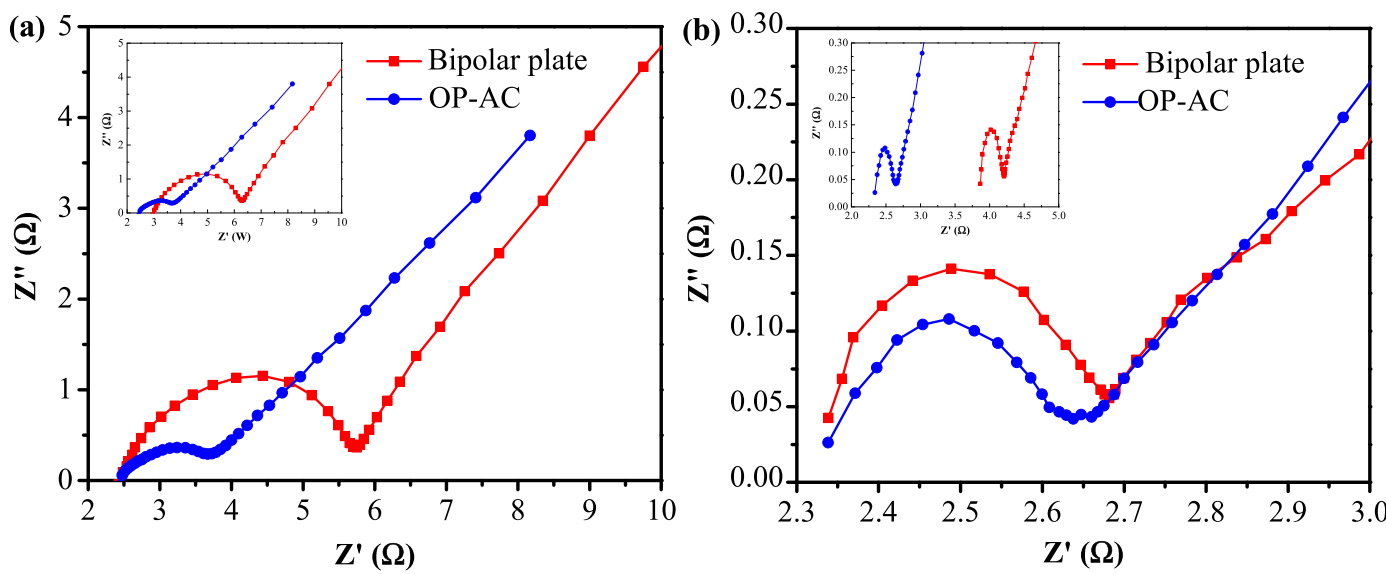

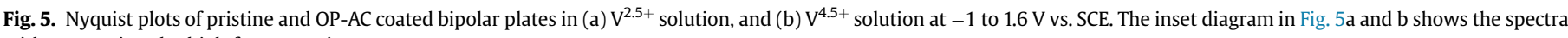
without moving the high frequency intercept. 

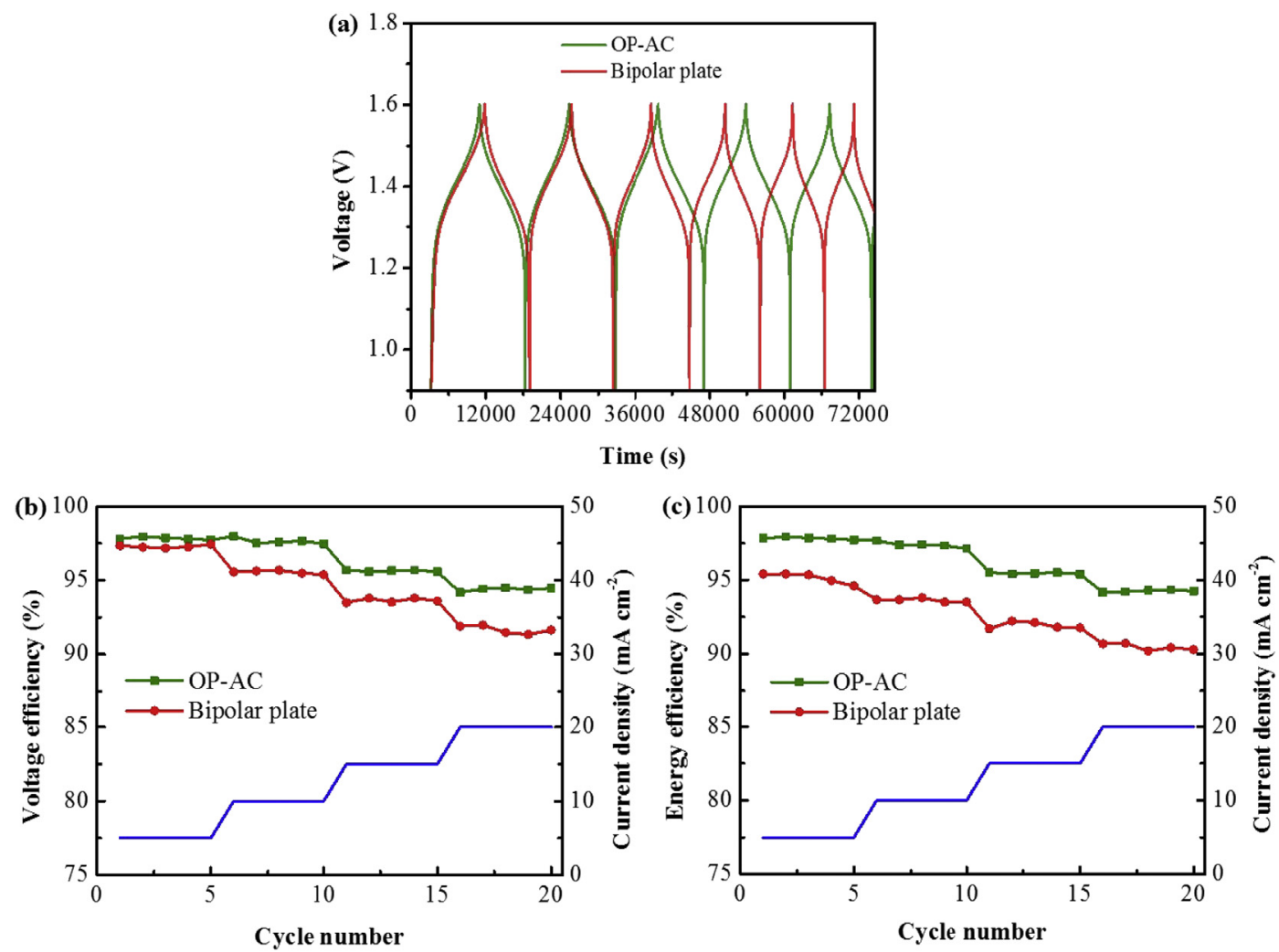

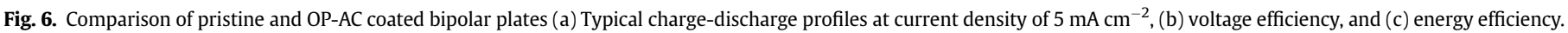

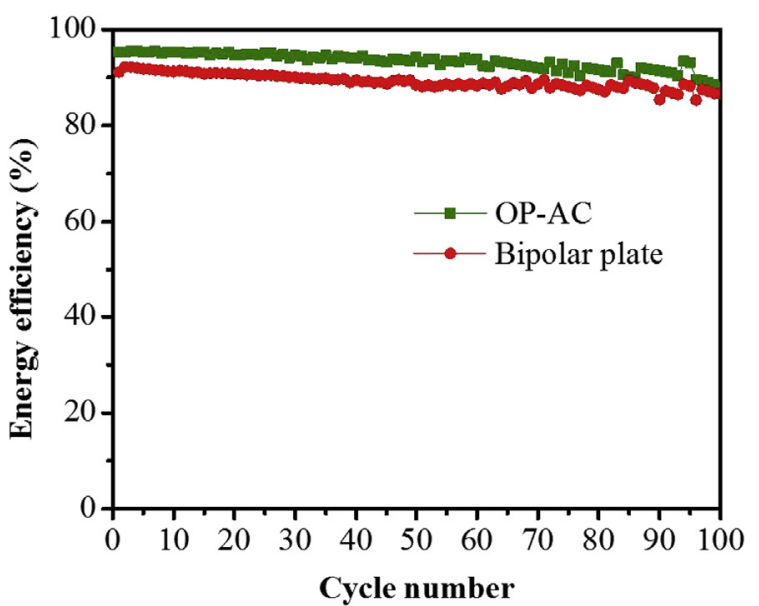

Fig. 7. Long term performances with pristine and OP-AC coated bipolar plates at a constant current density of $20 \mathrm{~mA} \mathrm{~cm}^{-2}$.

It should be noted that the advantage of energy efficiency of approx. $4 \%$ of the OP-AC reduced after 100 cycles. The faster drop of energy efficiency with OP-AC electrode was mainly due to the effect of longer cycle (charging and discharging) time as compared to that of pristine bipolar electrode. As both cells were tested in a constant voltage cut-off mode, therefore, longer cycle time (or higher SoC) was obtained for the cell with OP-AC electrode, due to the higher voltage efficiency. The longer cycle time of OP-AC increased crossover, i.e. increased electrolyte imbalance, which resulted in the higher reversible drop of energy efficiency and capacity.
Table 2

Average coulombic, energy and voltage efficiencies of pristine and OP-AC coated bipolar plates in VRB.

\begin{tabular}{|c|c|c|c|c|c|c|}
\hline \multirow[t]{2}{*}{ Current density $\left(\mathrm{mA} \mathrm{cm}^{-2}\right)$} & \multicolumn{3}{|c|}{$\begin{array}{l}\text { Bipolar plate } \\
\text { (Pristine) }\end{array}$} & \multicolumn{3}{|c|}{ OP-AC } \\
\hline & CE\% & EE\% & VE\% & CE\% & $\mathrm{EE} \%$ & VE\% \\
\hline 5 & 97.8 & 95.2 & 97.3 & 99.9 & 97.8 & 97.8 \\
\hline 10 & 98.0 & 93.6 & 95.5 & 99.7 & 97.4 & 97.6 \\
\hline 15 & 98.2 & 91.9 & 93.6 & 99.8 & 95.5 & 95.6 \\
\hline 20 & 98.7 & 90.5 & 91.7 & 99.9 & 94.3 & 94.4 \\
\hline $20^{\mathrm{a}}$ & 97.9 & 89.2 & 91.1 & 99.6 & 93.1 & 93.5 \\
\hline
\end{tabular}

Each average value is obtained from 5 charge-discharge cycles unless mentioned, and repeated twice.

a Efficiency values are average of 100 charge-discharge cycles.

\section{Conclusion}

High surface area activated carbon has been synthesized from abundantly available bio-waste (orange peel) to be used as potential electrode for VRB. The OP-AC coated bipolar plate exhibited improved electrochemical properties toward the vanadium redox couple reactions compared to the pristine electrode. The improved electro-catalytic activity of OP-AC can be attributed to the synergistic effect of high surface area and the presence of rich oxygencontaining functional groups. The VRB performance in a static cell shows higher voltage and energy efficiencies for OP-AC electrode than the pristine electrode at all current densities tested. The results indicate OP-AC to be a promising electrode for VRB applications. We can also consider OP-AC as one of the precursors to produce conducting plastics to lower the VRB stack cell weight and cost. 


\section{Acknowledgements}

The authors gratefully acknowledge Agency for Science, Technology and Research (A*STAR)/Singapore International Graduate Award (SINGA) and Nanyang Technological University, Singapore for funding support.

\section{References}

[1] H.D. Yoo, E. Markevich, G. Salitra, D. Sharon, D. Aurbach, Mater. Today 17 (2014) 110-121.

[2] B. Dunn, H. Kamath, J.-M. Tarascon, Science 334 (2011) 928-935.

[3] A. Parasuraman, T.M. Lim, C. Menictas, M. Skyllas-Kazacos, Electrochimica Acta 101 (2013) 27-40.

[4] P. Alotto, M. Guarnieri, F. Moro, Renew. Sustain. Energy Rev. 29 (2014) $325-335$.

[5] G. Kear, A.A. Shah, F.C. Walsh, Int. J. Energy Res. 36 (2012) 1105-1120.

[6] M. Ulaganathan, A. Jain, V. Aravindan, S. Jayaraman, W.C. Ling, T.M. Lim, M.P. Srinivasan, O. Yan, S. Madhavi, J. Power Sources 274 (2015) 846-850.

[7] C. Yao, H. Zhang, T. Liu, X. Li, Z. Liu, J. Power Sources 218 (2012) 455-461.

[8] B. Li, M. Li, Z. Gu, X. Nie, C. Wei, V. Wang, W. Sprenkle, Wang, Nano Lett. 14 (2014) 158-165.

[9] S. Winardi, S.C. Raghu, M.O. Oo, Q. Yan, N. Wai, T.M. Lim, M. Skyllas-Kazacos, J. Membr. Sci. 450 (2014) 313-322.

[10] A. Bhattarai, N. Wai, R. Schweiss, A. Whitehead, T.M. Lim, H.H. Hng, J. Power Sources 341 (2017) 83-90.

[11] M. Biswal, A. Banerjee, M. Deo, S. Ogale, Energy \& Environ. Sci. 6 (2013) 1249-1259.

[12] M. Sevilla, R. Mokaya, Energy \& Environ. Sci. 7 (2014) 1250-1280.

[13] R. Wang, P. Wang, X. Yan, J. Lang, C. Peng, Q. Xue, ACS Appl. Mater. Interfaces 4 (2012) 5800-5806.

[14] G.K. Parshetti, S. Chowdhury, R. Balasubramanian, Fuel 148 (2015) 246-254.

[15] A. Jain, C. Xu, S. Jayaraman, R. Balasubramanian, J.Y. Lee, M.P. Srinivasan, Microporous Mesoporous Mater. 218 (2015) 55-61.

[16] L. Wang, Y. Guo, B. Zou, C. Rong, X. Ma, Y. Qu, Y. Li, Z. Wang, Bioresour. Technol. 102 (2011) 1947-1950.

[17] I.I. Gurten, M. Ozmak, E. Yagmur, Z. Aktas, Biomass Bioenergy 37 (2012) $73-81$.
[18] FAS-USDA, Foreign Agricultural Service-United States Department of Agriculture, Citrus world Mark. trade (2014). https://apps.fas.usda.gov/psdonline/ circulars/citrus.pdf.

[19] M.E. Fernandez, G.V. Nunell, P.R. Bonelli, A.L. Cukierman, Industrial Crops Prod. 62 (2014) 437-445.

[20] F.-M. Pellera, A. Giannis, D. Kalderis, K. Anastasiadou, R. Stegmann, J.-Y. Wang, E. Gidarakos, J. Environ. Manag. 96 (2012) 35-42.

[21] A.B. Pérez-Marín, A. Ballester, F. González, M.L. Blázquez, J.A. Muñoz, J. Sáez V.M. Zapata, Bioresour. Technol. 99 (2008) 8101-8106.

[22] A.B. Pérez-Marín, V.M. Zapata, J.F. Ortuño, M. Aguilar, J. Sáez, M. Lloréns, J. Hazard. Mater. 139 (2007) 122-131.

[23] M.M. Titirici, A. Thomas, S.-H. Yu, J.-O. Müller, M. Antonietti, Chem. Mater. 19 (2007) 4205-4212.

[24] A.E. Nemr, O. Abdelwahab, A. El-Sikaily, A. Khaled, J. Hazard. Mater. 16 (2009) 102-110.

[25] M.E. Fernandez, B. Ledesma, S. Román, P.R. Bonelli, A.L. Cukierman, Bioresour Technol. 183 (2015) 221-228.

[26] K.Y. Foo, B.H. Hameed, Bioresour. Technol. 104 (2012) 679-686.

[27] X. Rui, A. Parasuraman, W. Liu, D.H. Sim, H.H. Hng, Q. Yan, T.M. Lim, M. Skyllas-Kazacos, Carbon 64 (2013) 464-471.

[28] W. Li, J. Liu, C. Yan, Electrochimica Acta 79 (2012) 102-108.

[29] C. Flox, M. Skoumal, J. Rubio-Garcia, T. Andreu, J.R. Morante, Appl. Energy 109 (2013) 344-351.

[30] W.N.-F. SU An-Qun, L.I.U. Su-Qin, W.U. Tao, P.E.N.G. Sui, in: Acta Phys, -Chim. Sin, 2012, pp. 1387-1392.

[31] S. Storck, H. Bretinger, W.F. Maier, Appl. Catal. A General 174 (1998) 137-146.

[32] P. Sennu, V. Aravindan, M. Ganesan, Y.-G. Lee, Y.-S. Lee, ChemSusChem 9 (2016) 849-854.

[33] B. Xu, Y. Chen, G. Wei, G. Cao, H. Zhang, Y. Yang, Mater. Chem. Phys. 124 (2010) 504-509.

[34] S.T. Senthilkumar, B. Senthilkumar, S. Balaji, C. Sanjeeviraja, R. Kalai Selvan, Mater. Res. Bull. 46 (2011) 413-419.

[35] A. Jänes, H. Kurig, E. Lust, Carbon 45 (2007) 1226-1233.

[36] P. Sennu, H.-J. Choi, S.-G. Baek, V. Aravindan, Y.-S. Lee, Carbon 98 (2016) 58-66.

[37] S.M. Taylor, A. Pătru, E. Fabbri, T.J. Schmidt, Electrochem. Commun. 75 (2017 13-16.

[38] S. Rudolph, U. Schröder, I.M. Bayanov, D. Hage, J. Electroanal. Chem. 728 (2014) 72-80

[39] S. Corcuera, M. Skyllas-Kazacos, Eur. Chem. Bull. 1 (2012) 511-519. 